\title{
Pelatihan Pembuatan Video Dengan Power Point Sebagai Media Pembelajaran Guru Sekolah Dasar
}

\author{
Despita Meisak ${ }^{1}$, Manja Purnasari ${ }^{2}$, Nurhayati ${ }^{3}$ \\ Yessi Hartiwi ${ }^{4}$ \\ 1,2,3,4 Universitas Dinamika Bangsa \\ email : despitam88@gmail.com¹, purnasari1405@gmail.com², nurhayatihalim@gmail.com³, \\ yessiharti26@gmail.com ${ }^{4}$
}

\begin{abstract}
The availability of teaching materials is one of the key factors in teaching and learning activities. Teaching materials can be used to help students understand the topic of the content of the lesson. During the Covid - 19 pandemic, SDN 13 Jambi City carried out online/online teaching and learning activities, where the media used for online learning was the WhastApp group. In practice the teacher only sends assignments via WhatsApp groups, This is certainly less effective because students have to do the assignments given without any explanation of the material in advance by the teacher. Students are required to understand the learning materials contained in the theme book themselves before being able to do the assignments given by the teacher. The result of this activity are expected that teachers have skills in making teaching materials in the form of learning videos that are easily understood by students.
\end{abstract}

Keywords: learning video, online, powerpoint.

\begin{abstract}
Abstrak
Ketersediaan bahan ajar merupakan salah satu faktor kunci dalam kegiatan belajar mengajar. Bahan ajar bisa digunakan untuk membantu siswa memahami tentang topik isi dari pelajaran. Selama masa pandemi Covid-19 ini SDN 13 Kota Jambi melaksanakan kegiatan belajar mengajar secara online/daring, dimana media yang digunakan untuk pembelajaran online adalah WhatsApp Group. Dalam Pelaksanaannya guru hanya mengirimkan tugas melalui WhatsApp Group, hal ini tentu kurang efektif karena siswa harus mengerjakan tugas yang diberikan tanpa ada penjelasan materi terlebih dahulu oleh guru. Siswa dituntut untuk memahami sendiri materi pembelajaran yang terdapat dalam buku tema sebelum dapat megerjakan tugas-tugas yang diberikan oleh guru. Hasil dari Kegiatan ini diharapkan guruguru memiliki keterampilan dalam membuat bahan ajar berupa video pembelajaran yang mudah di pahami oleh siswa.
\end{abstract}

Kata Kunci: video pembelajaran, daring, powerpoint.

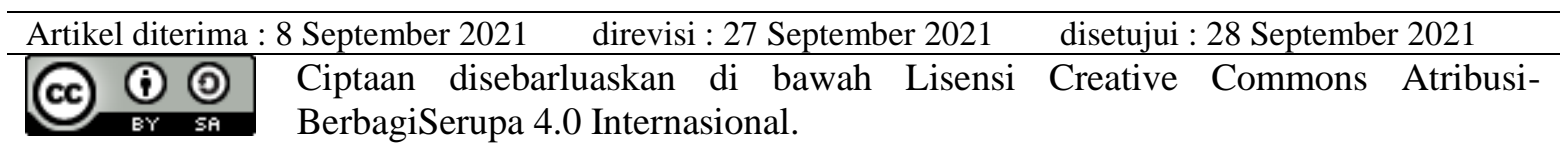




\section{Pendahuluan}

Perkembangan teknologi informasi saat ini telah merambah keseluruh bidang kehidupan manusia termasuk bidang pendidikan. Proses belajar mengajar menjadi peranan sangat penting dalam dunia pendidikan. Peran guru sebagai seorang pendidik, pengajar, dan pembimbing haruslah dapat membuat media pembelajaran yang menarik agar materi pelajaran yang disampaikan dapat dipahami oleh para siswa. Dalam teknologi informasi ada banyak media pembelajaran yang dapat digunakan untuk proses pembelajaran salah satunya adalah Ms.Power Point. Dengan media pembelajaran siswa akan lebih termotivasi untuk belajar (Amanda et al., 2019). Pengunaan media belajar untuk meningkatkan minat belajar siswa (Supriyono, 2019).

Microsoft Power Point adalah program aplikasi yang dapat digunakan untuk hal presentasi, baik itu presentasi pelajaran, tugas kuliah, presentasi bisnis, dan karya penelitian. Microsoft Power Point menampung poin-poin penting pembelajaran sehingga dapat dimengerti oleh para siswa. Terdapat berbagai fitur-fitur yang disediakan oleh Ms.Power Point mulai dari template yang menarik, animasi, transisi, sampai dengan pembuatan video pembelajaran dengan menggunakan webcam. Power point memiliki nilai $89 \%$ yang artinya power point sudah sangat layak digunakan untuk media pembelajaran (Jayusman et al., 2017). Menurut pendapat Dewi \& Manuaba (2021) bahwa power point sebagai media pembelajaran digunakan agar guru mempunyai metode pembelajaran yang lebih menarik dan inovatif.

Ditengah kondisi pandemi Covid19 saat ini menimbulkan permasalahan dalam kegiatan belajar mengajar yang menjadi kurang efektif karena dilakukan secara daring, Model pembelajaran yang dilakukan secara daring lebih dikenal dengan istilah online learning (ollearning) model ini berbeda dengan model pembelajaran secara konvensional (conventional learning) terlihat dari proses interaksinya (Sukardi \& Rozi, 2019). Guru hanya memberikan tugas-tugas tanpa menjelaskan materi pembelajaran terlebih dahulu hal ini membuat para siswa merasa kesulitan dalam belajar karena harus memahami materi pelajaran sendiri dan bingung dalam mengerjakan tugas. Permasalahan saat inilah yang sedang terjadi di SD Negeri 13 Kota Jambi, yaitu guru hanya mengirim materi pelajaran lewat media sosial WhatsApp Group sehingga berakibat pada menurunnya minat belajar para siswa.

Untuk itu diperlukan adanya pelatihan untuk menambah pengetahuan dan wawasan para guru tentang penggunaan Ms.Power Point sebagai media pembelajaran untuk membuat video bahan ajar agar lebih menarik lagi sehingga materi tersampaikan secara baik kepada siswa.

\section{Metode Pelaksanaan}

Kegiatan pengabdian kepada masyarakat ini dilaksanakan pada tanggal $15 \mathrm{Juli}$ 2021. Adapun peserta dari kegiatan pengabdian kepada masyarakat ini adalah para guru dari SD Negeri 13 Kota Jambi sebanyak 14 orang. Lokasi kegiatan pengabdian kepada masyarakat berada di ruang rapat yang ada di SD Negeri 13 Kota Jambi dengan tetap menerapkan protokol kesehatan.

Kegiatan pengabdian kepada masyarakat dilakukan secara langsung berupa pelatihan pembuatan video pembelajaran menggunakan power point oleh dosen Universitas Dinamika Bangsa. Kegiatan ini dilakukan dalam beberapa tahap. Tahap pertama, pengajuan surat izin kepada Kepala SD Negeri 13 Kota Jambi sebelum kegitan pelaksanaan. Tahap kedua, tim menyusun materi dan modul dengan mempertimbangkan peserta pelatihan, sarana dan prasarana serta waktu yang tersedia. Tahap ketiga, kegiatan pelaksanaan yang diawali dengan mempersiapkan laptop, infokus, dan modul untuk peserta belajar mandiri. Selanjutkan penyampaian materi 
dan pendampingan kepada peserta pelatihan.

\section{Hasil Dan Pembahasan}

Pelaksanaan kegiatan ini dilakukan dalam bentuk ceramah, tanya jawab, dan praktek yang berhubungan dengan materi pengenalan Microsoft Power Point. Kegiatan ini diawali dengan pemberian materi sesuai petunjuk modul kepada setiap peserta yang dilakukan oleh 4 orang narasumber yaitu 1 orang selaku instruktur untuk menjelaskan sekaligus mempraktekkan setiap materi dan 3 orang anggota lainnya memberikan bimbingan secara langsung kepada peserta yang mengalami kendala dalam mengikuti proses instruksi.

Ada 2 materi yang disampaikan oleh narasumber. Materi pertama yang diberikan adalah panduan pembuatan video ajar menggunakan powerpoint (windows) tanpa webcam. Instruktur menjelaskan tahapan awal pembuatan video ajar yang berisi slide materi dan narasi tanpa disertai oleh video yang menunjukan wajah dosen sampai dengan tahapan akhir ketika video siap digunakan. Sebelum masuk kedalam tahap awal pembuatan video, anggota tim menginstal windows 10 pada laptop peserta, setelah penginstalan selesai, instruktur menjelaskan langkah-langkah pembuatan video diawali dengan membuka Ms.Power Point, kemudian peserta diberi waktu sekitar 15 menit untuk membuat materi pembelajaran di Ms.Power point.

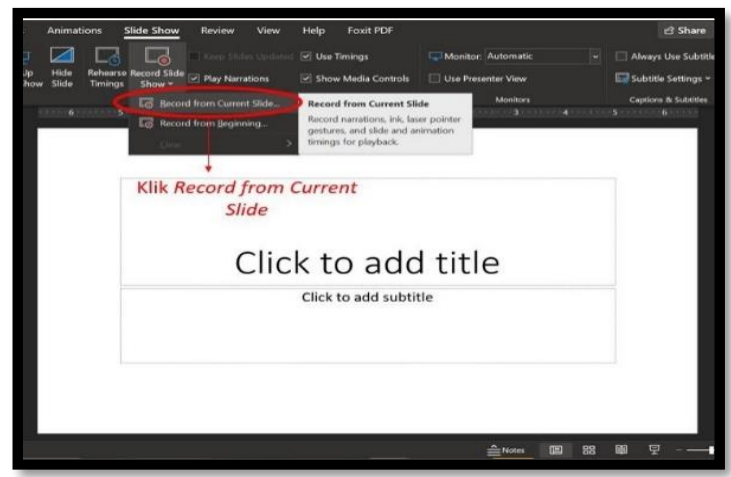

Gambar 1. Memulai record video

Setelah para peserta selesai membuat materi pada Ms.Power Point, instruktur kembali menjelaskan cara membuat video pembelajaran di bantu oleh anggota tim untuk memastikan bahwa peserta mengikuti instruksi yang diberikan. Langkah dalam membuat video pembelajaran nya yaitu dengan memilih menu "slide show" lalu pilih "Record from current slide" Pada menu bar power point.

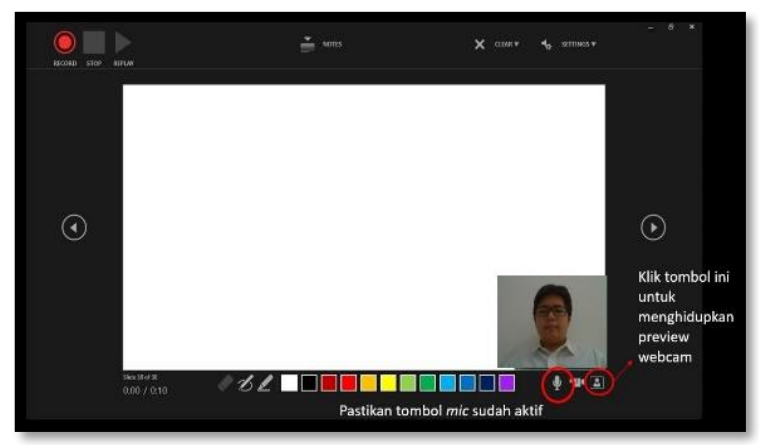

Gambar 2. Membuat video pembelajaran

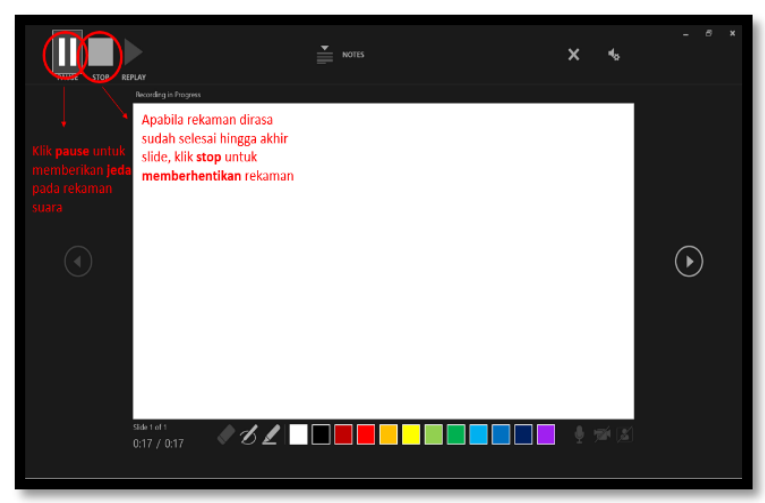

Gambar 3. Mulai merekam materi pelajaran

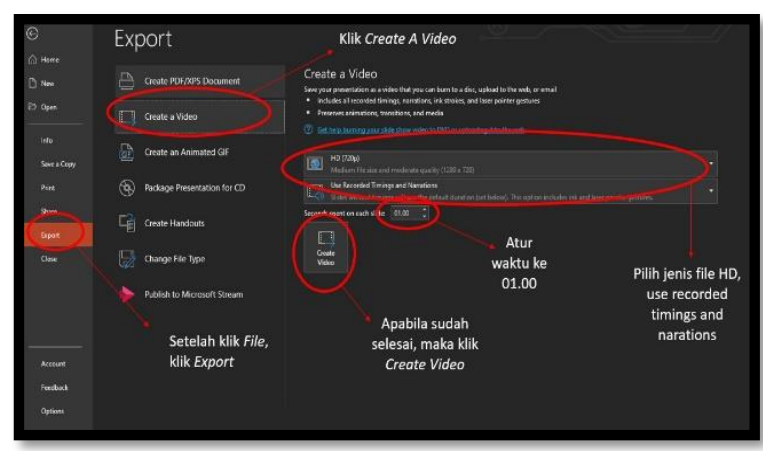

Gambar 4. Menyimpan hasil rekaman format video

Setelah tampilan recording muncul, kemudian di bagian kanan bawah klik icon Mic (untuk audio) maka peserta sudah bisa membuat video pembelajaran dengan 
audio suara, jika sudah selesai maka video pembelajaran bisa dibuat, dengan mengklik tombol Record bewarna merah di pojok kanan atas dan klik tombol "STOP" jika sudah selesai merekam video pembelajaran, Klik tombol Replay untuk mengecek hasil rekaman video. Setelah menjelaskan langkah-langkahnya peserta diminta untuk mencoba mempraktekkannya di laptop masing-masing dibantu oleh anggota tim.

Dilanjutkan materi kedua yaitu membuat video pembelajaran dengan "Webcam" (tampil wajah), agar dapat menampilkan wajah guru bersangkutan materi pembelajaran pada video, langkahlangkahnya sama seperti yang di awal, hanya perlu mengklik icon Audio dan Preview Webcam di pojok kanan bawah pada tampilan Recording power point nya. Jika sudah selesai, peserta diminta untuk meng Save hasil rekaman yang dibuat dengan cara mengklik File - ExportCreate a video, kemudian memilih jenis file $H D(720 p)$ dan " use recorded timings and narrations" dan pada "second spent on each slide" isi 1 detik, jika pengaturan sudah selesai, selanjutnya meng klik "Create a Video" untuk mengubah file Ms.Power Point menjadi video pembelajaran.

Berikut adalah foto-foto kegiatan pelatihan pembuatan video pembelajaran menggunakan power point untuk guru pada SD Negeri 13 Kota Jambi. Selama penyampaian materi, seluruh peserta mengikuti kegiatan ini dengan antusias dan perhatian yang tinggi, hal ini terlihat dari antusias peserta dalam mengikuti prakteknya, dan juga antusias dalam mengajukan pertanyaan.

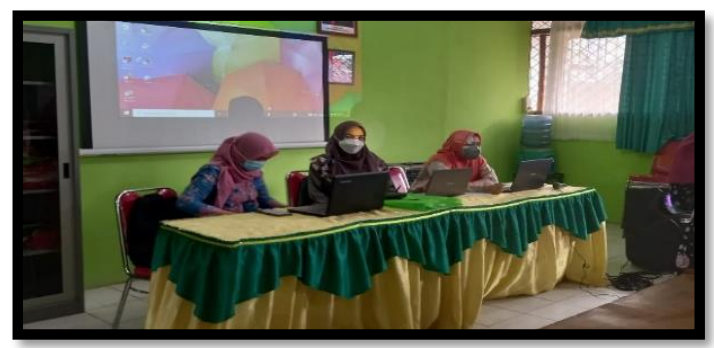

Gambar 5. Tim dosen

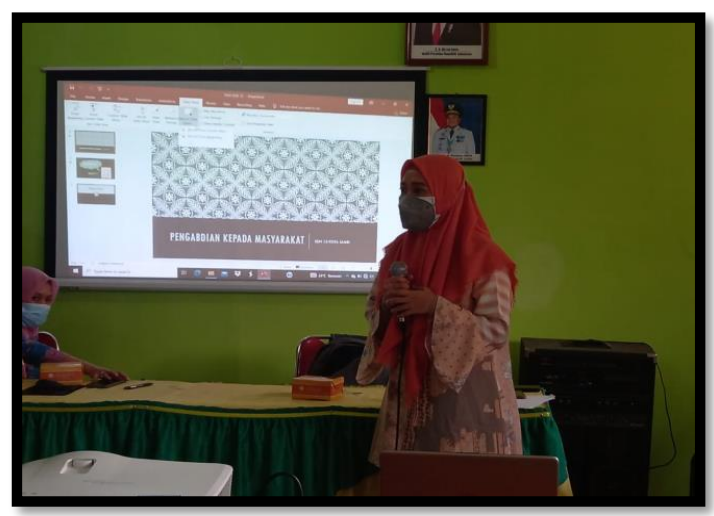

Gambar 6. Penyampaian materi

Berdasarkan hasil pengamatan yang dilakukan narasumber terhadap peserta pelatihan ternyata masih peserta pelatihan yang baru pertama kali membuat video ajar menggunakan Ms.Power Point.
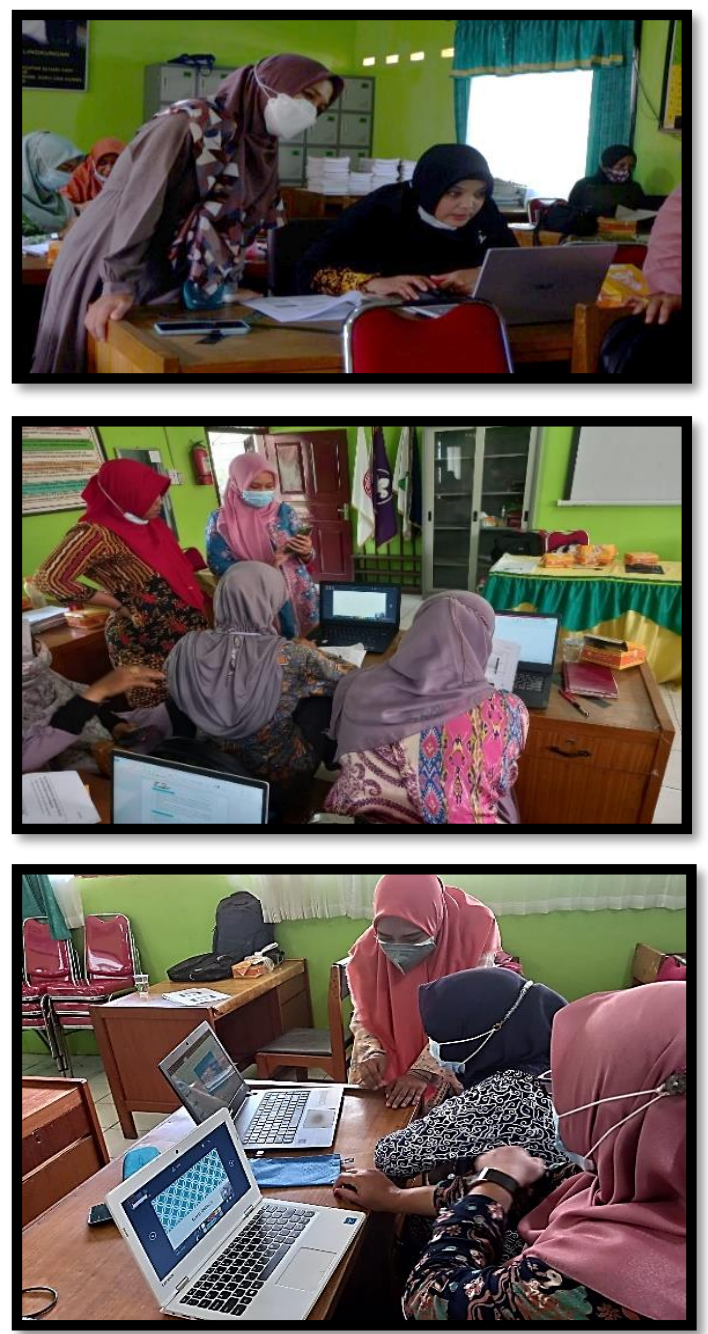

Gambar 7. Bimbingan kepada peserta 
Selama proses kegiatan, peserta diberikan kesempatan untuk mengajuan pertanyaan yang belum dimengerti. Peserta sangat antusias dalam mengajukan pertanyaan kepada narasumber.

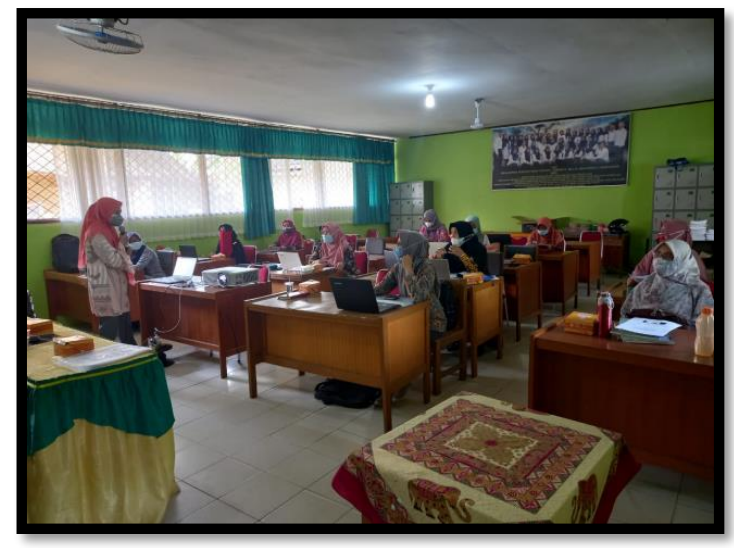

Gambar 8. Penyampaian materi kedua
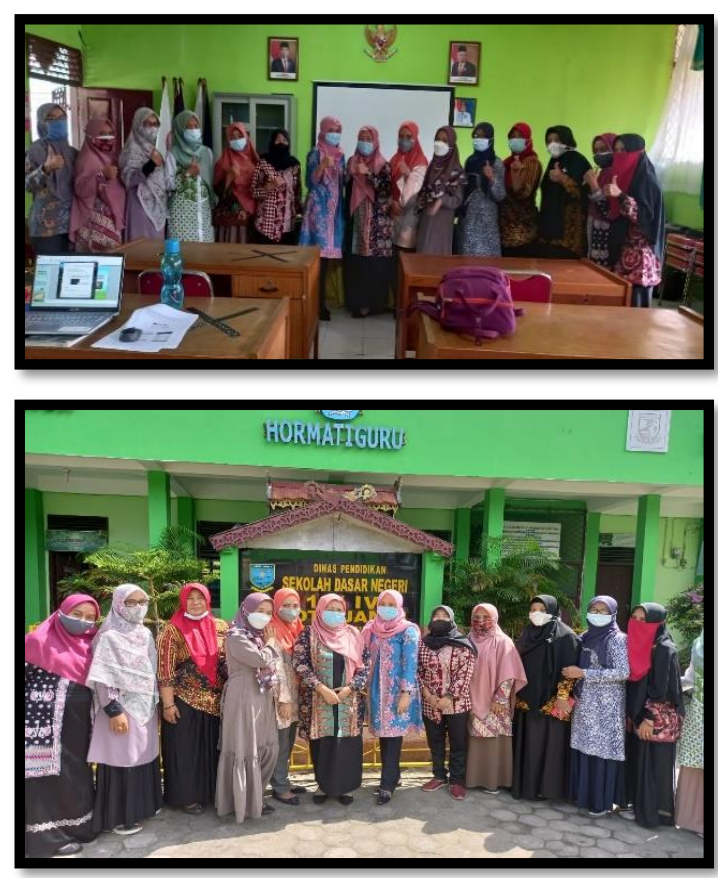

Gambar 9. Foto bersama

Kegiatan pelatihan pembuatan video ajar dengan power point ini sangat bermanfaat bagi peserta. Peserta dapat menambah wawasan dan pengetahuan dalam menggunakan Ms.Power Point yang digunakan untuk pembuatan video pelajaran kepada siswa siswi secara online maupun offline sehinngga materi yang disampaikan dapat dipahami oleh siswa siswi.

\section{Simpulan}

\section{Penutup}

Kegiatan pelatihan membuat media pembelajaran dengan power point sangat diperlukan bagi guru-guru di SD Negeri 13 Kota Jambi, apalagi di dalam kondisi covid yang mana siswa siswi melakukan pembelajaran jarak jauh yaitu secara online/daring, dimana guru-guru di tuntut untuk kreatif dalam membuat media pembelajaran agar materi pembelajaran yang disampaikan dapat dipahami oleh siswa dengan baik.

Kegiatan pelatihan membuat video pembelajaran dengan power point ini sangat dibutuhkan oleh guru-guru sebagai salah satu media yang bisa digunakan untuk membuat media pembelajaran menarik untuk siswa siswi, yang mana nantinya hasil video pembelajaran dapat di akses secara online ataupun offline, sehingga tujuan dari pembelajaran pun bisa disampaikan.

\section{Saran}

Diharapkan adanya kerjasama berkelanjutan ke depan nya untuk pelatihan - pelatihan lainnya yang dapat menunjang kinerja guru di SD Negeri 13 Kota Jambi, sebaiknya guru - guru I SD Negeri 13 Kota jambi perlu menerapkan keterampilan komputer untuk menambah wawasan dan pengetahuan dibidang teknologi terutama untuk mengembangkan media belajar anak berbasis ICT.

\section{Ucapan Terimakasih}

Proses pelaksanaan kegiatan pengabdian kepada masyarakat ini tidak lepas dari bantuan dan dukungan dari Universitas Dinamika Bangsa dan Kepala Sekolah SD Negeri 13 Kota Jambi serta berbagai pihak, atas bantuan dan bimbingannya maka penulis mengucapkan banyak terima kasih sebesar-besarnya, sehingga kegiatan ini dapat berjalan dengan baik.

\section{Daftar Pustaka}


Amanda, N., Reffiane, F., \& Arisyanto, P. (2019). Pengembangan Media Budel (Buku Berjendela) pada Tema Keluargaku. Jurnal Penelitian Dan Pengembangan Pendidikan, 3(2), 97104.

Dewi, N. L. P. S., \& Manuaba, I. B. S. (2021). Pengembangan Media Pembelajaran Powerpoint Interaktif Pada Mata Pelajaran IPA Siswa Kelas VI SD. Jurnal Penelitian Dan Pengembangan Pendidikan, 5(1).

Jayusman, I., Gurdjita, G., \& Shavab, O. A. K. (2017). Pengembangan Media Pembelajaran Multi Media Power Point Pada Mata Kuliah Sejarah Asia Timur. Candrasangkala: Jurnal Pendidikan Dan Sejarah, 3(1), 37-42.

Sukardi, S., \& Rozi, F. (2019). Pengaruh Model Pembelajaran Online Dilengkapi Dengan Tutorial Terhadap Hasil Belajar. JIPI (Jurnal Ilmiah Penelitian Dan Pembelajaran Informatika), 4(2), 97-102.

Supriyono, S. (2019). Pentingnya Media Pembelajaran Untuk Meningkatkan Minat Belajar Siswa Sd. Edustream: Jurnal Pendidikan Dasar, 2(1), 4348. 